\title{
Una nueva eSPeCie de Biophytum (OxAlidaceae) DEL SUR DE MÉXICO
}

\author{
Francisco G. Lorea-Hernández Y y Carlos Durán-Espinosa \\ Instituto de Ecología, A.C., Xalapa, Veracruz \\ 1'Autor para la correspondencia: francisco.lorea@inecol.edu.mx
}

\begin{abstract}
Resumen: Se describe e ilustra a Biophytum latifolium como especie nueva. Se discuten las semejanzas y diferencias con las especies del área mesoamericana y se presenta una clave para distinguir las tres especies del género que crecen en México. Palabras clave: Biophytum, bosque tropical perennifolio, flora de México, flora de Veracruz, Oxalidaceae.
\end{abstract}

\begin{abstract}
The new species Biophytum latifolium is described and illustrated. Similarities and differences with other species from the Mesoamerican region are discussed and a key for the three species of the genus found in Mexico is presented.

Key words: Biophytum, flora of Mexico, flora of Veracruz, Oxalidaceae, tropical rain forest.
\end{abstract}

$\boldsymbol{B}^{\text {i }}$ iophytum es uno de los tres géneros de la familia Oxaidaceae que crecen naturalmente en América. Es un género pantropical con alrededor de 75 especies que se distribuyen en mayor proporción en América tropical (Knuth, 1930; Lourteig, 1980). En el área mesoamericana se conocen siete especies, la mayoría con áreas de distribución no muy extensas, habitando sobre todo en bosques tropicales perennifolios y bosques húmedos de montaña, desde cerca del nivel del mar y hasta los $1,300(-1,800) \mathrm{m}$ de altitud (Lourteig, 1980; Wendt, 1987; Burger, 1991; Nelson, 1993; Sidwell, 2012). Por lo común son plantas terrestres que crecen en áreas húmedas, a veces cerca de cursos de agua permanente; una especie se ha registrado creciendo aparentemente como epífita.

Durante el desarrollo de un inventario florístico en áreas poco estudiadas del sur del estado de Veracruz se encontraron individuos de una especie de Biophytum, que al ser cotejados con la literatura y material de herbario disponible, se concluyó que correspondían a una especie aún no descrita. Previamente se conocían dos especies de este género en México: Biophytum cowanii T.Wendt y B. dendroides (Kunth) DC.

Biophytum latifolium Durán-Esp. et Lorea-Hern., sp. nov. (Figura 1).

A congeneris foliis ellipticis vel obovatis, plerumque $5-8 \mathrm{~cm}$ latis, foliolis saepe 5-8 jugatis, plerumque 15-40 × 10-20 $\mathrm{mm}$, inflorescentiis breviter $(2-7 \mathrm{~mm})$ pedunculatis, pedicellis $12-19 \mathrm{~mm}$, pedicellis et calycibus pubescentibus, trichomatibus partim glanduliferis, staminibus fertilibus non nisi quinque diversa est.

TIPO: México, Veracruz, municipio de Las Choapas, Rancho "El Milagro", $5 \mathrm{~km}$ en línea recta al suroeste $\left(202^{\circ}\right)$ de la colonia Nueva Tabasqueña, $17^{\circ} 31^{\prime} 48^{\prime \prime}$ N, 94 $01^{\circ}$ '44" O, 115 m s.n.m., 8/10/2002, E. López P. 347 (Holotipo: XAL; Isotipos: MEXU, ENCB, MO, NY).

Sufrútices rizomatosos, de 10-30 cm de alto. Tallos aéreos simples, de 1.5-6 mm de ancho, verdes a rojizos cuando vivos, café claro al secar, esparcidamente retrorso pubescentes a glabrescentes, con una banda muy densa de tricomas retrorsos al final de la sección áfila, corteza fisurada cuando seca. Hojas 6-13 por tallo, fasciculadas o muy próximas en el ápice del tallo, imparipinnadas, pero con el folíolo apical reducido a un mucrón de 1-2.5 mm de largo, pecíolo de (18-) 30-60 (-85) × 1-1.5 mm, pulvinado en la base, verde a rojizo cuando vivo, café claro al secar, pubescente, raquis plano a ligeramente acanalado en su cara adaxial, redondeado en su cara abaxial, pubescente, lámina de (5-) 9-15 (-23) × (3-) 5-8 $(-11) \mathrm{cm}$, elíptica a obovada en contorno, con (3-) 5-8 (-12) pares de folíolos, ascendentes, rectos a ligeramente falcados, todos enteros, oblicuos en la base, redondeados en el lado basiscópico, truncados y a veces con un somero lóbulo en el lado acroscópico, glabros por la haz, imperceptible pero 


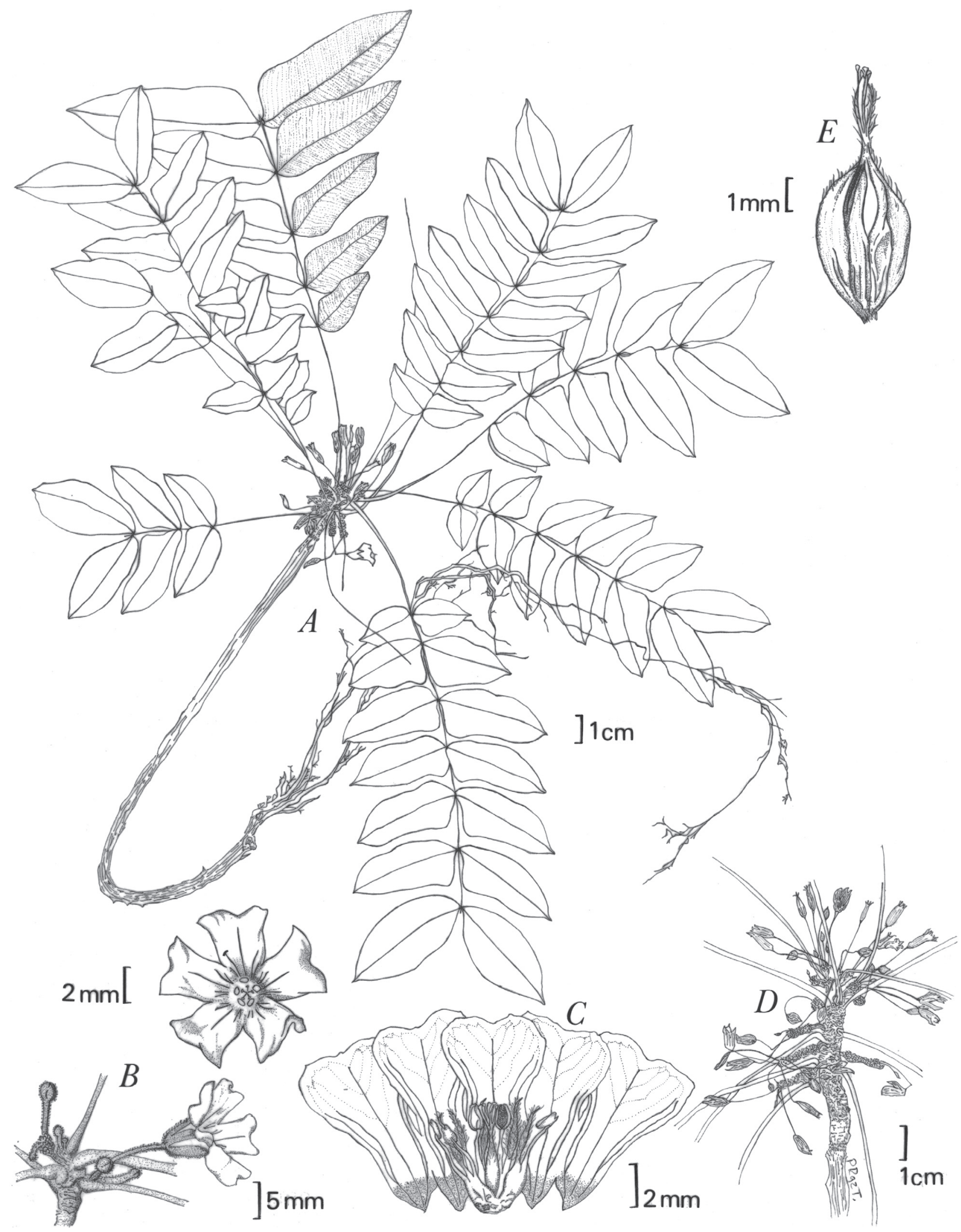

Figura 1. Biophytum latifolium Durán-Esp. et Lorea-Hern. A. Vista general de un tallo aéreo de la planta. B. Detalle de una flor y vista frontal de la corola. C. Corola abierta y extendida con detalle de los estambres. D. Inflorescencias en el ápice del tallo. E. Vista del fruto. 
densamente adpreso puberulentos y con diminutos tricomas glandulares esparcidos por el envés, glaucescentes, pilosos en el margen, mucronados, el mucrón de 0.5-1 mm de largo, peciolulados, peciólulos de 0.2-0.5 mm de largo, pulvinados, vena media excéntrica, sumergida en la haz y resaltada en el envés, los nervios secundarios numerosos, conspicuos en la haz y el envés, folíolos basales de (9-) 15-25 (-40) × (7-) 11-15 (-21) mm, ovados a elípticos, de ápice obtuso o agudo, foliolos medios de (15-) 25-50 (-60) × (9-) 12-18 (-23) $\mathrm{mm}$, oblongos, de ápice agudo u obtuso, folíolos apicales de (25-) 35-45 (-53) × (10-) 15-20 mm, oblongo-elípticos, con la base excavada en su lado acroscópico y el ápice agudo. Inflorescencias 1-13 por tallo, emergiendo de las axilas de las hojas, con frecuencia persistiendo aún después de la caída de las hojas, racemosas, muy densas, perennes, de 4-17 $\mathrm{mm}$ de largo sin contar los pedicelos, pedúnculo de 2-4.5 (-7) $\times$ 0.8-1.5 mm, hirsuto, pronto glabrescente, brácteas de 0.7-1.5 (-2) mm de largo, triangulares, gruesas, aquilladas, glabras, bractéolas de 0.5-0.7 mm de largo, ovado-deltoides, aquilladas, pilosas en su cara abaxial, pronto glabrescentes, aglomeradas, pedicelos de 12-19 × 0.2-0.4 mm, esparcidamente hirsutos y glandular-pilosos, verde-rojizos, patentes o ligeramente reflexos. Flores infundibuliformes, 1-3 en antesis a la vez por inflorescencia; sépalos 5, lanceolados a lanceolado-elípticos, de 5.5-6 × $1.5 \mathrm{~mm}$, con 9-12 nervios, verde-rojizos, con el ápice agudo, esparcidamente pubescentes y glandular-pilosos por fuera o glabrescentes, libres casi hasta la base, persistentes y ligeramente acrescentes (ca. 9 $\times 2.5 \mathrm{~mm}$ ) en el fruto; corola blanca o ligeramente rosada, de 7-9 mm de largo; pétalos 5, unidos por arriba de su base y hasta casi un cuarto de su longitud, lóbulos de la corola oblongos a transversalmente oblongos, de 3.5-5.5 × 3.5-6.3 $\mathrm{mm}$, con el ápice truncado, retuso, cada pétalo 5-lineolado, las líneas (venas) rosas a casi rojas; estambres 10, unidos por los filamentos de la base hasta casi la mitad de su longitud formando un tubo, dimorfos, 5 fértiles y 5 estériles, los fértiles con los filamentos de 3.5-4 mm de largo, aplanados, esparcidamente pilosos hacia la base, glabros en su mitad distal, anteras de ca. $0.7 \mathrm{~mm}$ de largo, oblongas, dorsifijas, introrsas, dehiscentes longitudinalmente, incluidas, de color crema, los estériles con los filamentos de 4.5-5 mm de largo, aplanados en su mitad basal, lanceolado-fusiformes en su mitad distal, pilosos, densamente así en su mitad distal, piloso glandulares en el ápice; pistilo de 5 carpelos, ovario oblongo, piloso, de $1.5 \times 0.6-0.8 \mathrm{~mm}$, estilos de $3-4 \mathrm{~mm}$ de largo, unidos $1 / 4-1 / 3$ de su longitud desde la base, ensanchados, estigmas pateliformes, con el borde fimbriado-eroso. Fruto una cápsula, de 5-5.2 ×3-4 mm, oblongo a subgloboso, con el ápice redondeado, glandular-puberulento, los estilos persistentes, con dehiscencia loculicida, valvas con 3-5 semillas. Semillas pardas, elipsoides, triquetras, de 1.8-2 $\times$ 0.8-1 mm, testa lisa, brillosas.

Distribución y ecología. Biophytum latifolium es hasta aho- ra conocida sólo de la localidad tipo; aunque localmente es rara, la población que se conoce está compuesta por muchos individuos. Crece en sitios pedregosos con mucha humedad, en un manchón de bosque tropical perennifolio dominado por Dialium guianense (Aubl.) Sandwith, Guatteria anomala R.E.Fr., Licania sparsipilis S.F.Blake, Sloanea tuerckheimii Donn.Sm., Sterculia mexicana R.Br. y Magnolia mexicana DC., entre otras especies. Comparte microhábitat con varios helechos, selaginelas y musgos. Se le encuentra en floración y fructificación de septiembre a diciembre.

Etimología. El epíteto específico para este taxón se refiere a una de las características que distinguen de manera clara a esta especie: lo ancho de sus hojas.

\section{Discusión}

Biophytum latifolium se distingue claramente de las otras especies del género en el área mesoamericana por las dimensiones de sus hojas y folíolos y por el número de pares de folíolos; es la especie con las hojas y folíolos más anchos conocidos hasta ahora y con el menor número de folíolos por hoja. La mayoría de las especies del área tienen hojas menores a $3.5 \mathrm{~cm}$ de ancho con folíolos de 2 a $7 \mathrm{~mm}$ de ancho y entre 12 a $25(-34)$ pares de folíolos por hoja. En tanto, B. latifolium por lo general tiene hojas de 5 a $8 \mathrm{~cm}$ de ancho con folíolos de 10 a $20 \mathrm{~mm}$ de ancho y hojas con 5 a 8 (-12) pares de folíolos. Desde el punto de vista vegetativo, B. latifolium es parecida a B. zunigae C.Nelson, una especie endémica de Honduras, al parecer epífita, que tiene hojas y folíolos amplios (hojas de 4.5 a $5.5 \mathrm{~cm}$ de ancho y folíolos hasta $1.2 \mathrm{~cm}$ de ancho) y pocos (12 a 15) pares de folíolos (datos obtenidos de la imagen del isotipo en MO, <www. tropicos.org/Image/58098>); no obstante, esta especie tiene una inflorescencia con un pedúnculo de 16 a $20 \mathrm{~cm}$ de largo, en tanto B. latifolium tiene pedúnculos de 0.2 a $0.7 \mathrm{~cm}$. Esta característica del pedúnculo muy corto lo comparte con $B$. falcifolium Lourteig y B. panamense Lourteig, especies endémicas de Costa Rica y Panamá y Panamá respectivamente, que también coinciden con B. latifolium en la presencia de un pedicelo largo, mayor a $10 \mathrm{~mm}$.

En cuanto a características de las flores, encontramos semejanzas con Biophytum cowanii, B. falcifolium, B. panamense y $B$. soukupii Lourteig, por tener la superficie exterior del cáliz cubierta por tricomas simples y glandulares y estambres y pistilo también pubescentes en diverso grado. Sin embargo, B. cowanii y B. soukupii difieren morfológicamente de B. latifolium por presentar, la primera, pedúnculos muy largos $(5-24 \mathrm{~cm})$, pedicelos glabros y estambres no glandular pubescentes, y la segunda por tener pedúnculos algo más largos (hasta $2 \mathrm{~cm}$ ), pedicelos muy cortos (hasta $3.5 \mathrm{~mm}$ ) y corolas glandular pubescentes. En los casos de inflorescencia y flor, B. panamense y B. latifolium son las más parecidas entre sí, por compartir pedúnculos muy 
Francisco G. Lorea-Hernández y CARLos Durán-Espinosa

Cuadro 1. Comparación de los caracteres más distintivos de las tres especies conocidas de Biophytum que crecen en México.

\begin{tabular}{llll}
\hline & B. latifolium & B. dendroides & B. cowanii \\
\hline Contorno de la hoja & elíptica a obovada & angostamente elíptica & angostamente elíptica \\
Ancho de la lámina foliar $(\mathrm{cm})$ & $3-11$ & $1-2$ & $1.5-3.5$ \\
Folíolos por hoja (pares) & $(3-) 5-8(-10)$ & $9-18(-26)$ & $11-26$ \\
Folíolos basales $(\mathrm{mm})$ & $9-40 \times 7-20$ & $1-2.5 \times 1.0-2.5$ & $3.5-11.0 \times 2.3-4.5$ \\
Folíolos medios $(\mathrm{mm})$ & $15-60 \times 9-23$ & $2.5-10 \times 1.5-7$ & $7-16 \times 2.6-5$ \\
Folíolos apicales $(\mathrm{mm})$ & $25-53 \times 10-20$ & $6-11 \times 2.5-5$ & $7-14 \times 2-5$ \\
Largo del pedúnculo $(\mathrm{cm})$ & $0.2-0.7$ & $1-8$ & $5-24$ \\
Inflorescencia & hirsuta, pronto glabrescente & densamente pilosa & glabra a ligeramente estrigosa-sericea \\
Largo de las brácteas $(\mathrm{mm})$ & $0.7-1.5(-2)$ & $3-7$ & $0.6-1$ \\
Largo de las bractéolas $(\mathrm{mm})$ & $0.5-0.7$ & $2-7$ & más pequeñas que las brácteas \\
Largo de los pedicelos $(\mathrm{mm})$ & $12-19$ & $1-5$ & $6-13$ \\
Superficie de los pedicelos & $\begin{array}{l}\text { esparcidamente hirsuta y } \\
\text { glandular-pilosa }\end{array}$ & $\begin{array}{l}\text { glabra o finamente } \\
\text { puberulenta }\end{array}$ & glabra \\
Pétalos & oblongos a transversalmente & espatulados a obovados, & ovado-elípticos, ápice \\
& & ápice ligeramente retuso & ampliamente obtuso
\end{tabular}

cortos, pedicelos largos y pubescentes con tricomas glandulares, además de cáliz y estambres con el mismo tipo de pubescencia.

Considerando lo anterior, resulta interesante observar que Biophytum latifolium tiene mayor parecido morfológico con especies que se encuentran distantes geográficamente hablando; una situación semejante a lo que halló Wendt (1987) sobre las relaciones de $B$. cowanii. Aunque se esperaría mayor relación con especies simpátricas, éstas (B. cowanii y $B$. dendroides (Kunth) DC.) son sustancialmente diferentes (Cuadro 1). En realidad es difícil establecer con base en la morfología con cuál especie tiene mayor relación $B$. latifolium. Igualmente, la forma en que se combinan los rasgos de las diferentes estructuras en esta especie no encaja del todo con alguno de los patrones reconocidos para las secciones del género propuestas por Knuth (1930). Con base en la morfología de su tallo e inflorescencias (tallos aéreos simples y pedúnculos o pedicelos reducidos), B. latifolium debería considerarse en la sección Dendroidea Knuth, pero las dimensiones de sus hojas (con folíolos de hasta $6 \times 2.3$ $\mathrm{cm}$ ) la ubicarían en la sección Grandifoliolata Knuth (cuyas inflorescencias tienen pedúnculos de varios centímetros de largo). Es claro, sin embargo, que la morfología de los folíolos de B. latifolium (angostamente oblongo-elípticos, obtusos a agudos en el ápice y mucronados) la relacionan más con la sección Dendroidea que con Grandifoliolata (de folíolos más bien oblongos y truncados a ligeramente redondeados en el ápice). Pareciera entonces necesario revisar la sistemática del género a fin de precisar mejor los subgrupos naturales dentro del mismo y esclarecer cuáles son los rasgos que les dan identidad y que en consecuencia los distinguen y relacionan entre sí.
Un comentario aparte merece la condición particular del androceo en Biophytum latifolium, constituido de cinco estambres fértiles y cinco estaminodios. Como se sabe, Biophytum es uno de los muy pocos géneros de angiospermas donde está documentado un sistema de entrecruzamiento heterostílico trimorfo (Weller, 1992). Sin embargo, dadas las características descritas del androceo en B. latifolium, es evidente que ese sistema no se presenta en esta especie. No podemos asegurar que el sistema de cruzamiento sea distílico, ya que no observamos variación en el tamaño relativo de los estilos con respecto a los estambres en los ejemplares revisados de $B$. latifolium. Pero la evidencia morfológica parece indicar que la condición tristílica puede perderse por diferentes vías. En ese sentido, es interesante resaltar que mientras en las otras especies mesoamericanas con sólo cinco estambres fértiles (B. falcifolium, B. mucronatum y $B$. panamense), los estambres cortos son los estériles, en $B$. latifolium ocurre lo contrario; en esta especie los estambres largos son los estériles.

Ejemplares adicionales examinados: México, Veracruz, Municipio de Las Choapas, Rancho "El Milagro", 5 km en línea recta al suroeste $\left(202^{\circ}\right)$ de la colonia Nueva Tabasqueña, E. López P. 645 (XAL), C. Gallardo H. et al. 3145, 3365, 3547 (XAL).

Clave para las especies de Biophytum que habitan en México.

1. Lámina foliar elíptica a obovada en contorno, de 3-11 cm de ancho. Folíolos por lo general 5-8 pares. Pedúnculo de 0.2-0.7 cm de largo y pedicelos esparcidamente hirsutos y glandular pilosos B. latifolium 
1. Lámina foliar linear en contorno, de $1-3.5 \mathrm{~cm}$ de ancho. Folíolos por lo general 9-26 pares. Pedúnculo de (0.4-)1$24 \mathrm{~cm}$ de largo y pedicelos glabros o puberulentos pero no glandular pilosos.

2. Pedúnculo densamente piloso, de (0.4-)1-8 cm de largo; pedicelos glabros o puberulentos, de $1-5 \mathrm{~mm}$ de largo B. dendroides

2. Pedúnculo glabro o ligeramente seríceo, de $5-24 \mathrm{~cm}$ de largo; pedicelos glabros, de 6-13 mm de largo

B. cowanii

A diferencia de Biophytum latifolium y B. cowanii, que hasta ahora son conocidas de las localidades tipo y un sitio más en el caso de la segunda, $B$. dendroides es una especie más o menos común en Chiapas, Oaxaca y Veracruz, y de manera disjunta en Jalisco (Ramírez-Delgadillo et al., 2010), desde 0 a 1,600 m s.n.m., tanto en áreas perturbadas como en bosques conservados, su distribución abarca el sur de México, toda Centroamérica y noroeste de Sudamérica hasta Bolivia.

\section{Agradecimientos}

La mayoría de las muestras de herbario estudiadas fueron colectadas como parte del proyecto CONACYT (R 32629N) "Perfeccionamiento de las colecciones y bases de datos del herbario XAL". Agradecemos la invitación de Javier Vaquera, propietario del Rancho El Milagro, a estudiar la flora del lugar. Efraín López coadyuvó de manera importante en el trabajo de campo. Lucio Lozada apoyó proporcionando parte de la literatura. El dibujo que acompaña la descripción fue realizado por Paola Rodríguez, a quien agradecemos su diligencia en la ejecución del mismo; la notación de las escalas fue delineada por Manuel Escamilla. Los comentarios de los revisores, Tom Wendt y Pablo Carrillo, ayudaron a mejorar el trabajo.

\section{Literatura citada}

Burger W.C. 1991. Flora Costaricensis: Family 98. Oxalidaceae. Fieldiana, Botany n.s. 28:2-16.

Knuth R. 1930. Biophytum. En: Engler A. Ed. Das Pflanzenreich Regni vegetalis conspectus IV (130), pp. 391-417, Verlag von H. R. Engelmann, Berlín.

Lourteig A. 1980. Flora of Panama 4. Family 84. Oxalidaceae. Annals of the Missouri Botanical Garden 67:823-850.

Nelson C. 1993. A new species of Biophytum (Oxalidaceae) from Honduras. Phytologia 75:190-191.

Ramírez-Delgadillo R., Vargas-Ponce O., Arreola-Nava H.J., Cedano-Maldonado M., González-Tamayo R., González-Villareal L.M., Harker M., Hernández-López L., Martínez-González R.E., Pérez-de la Rosa J.A., Rodríguez-Contreras A., Reynoso-Dueñas J.J., Villarreal-de Puga L.M. y Villaseñor-Ríos J.L. 2010. Catálogo de Plantas Vasculares de Jalisco. Universidad de Guadalajara/Sociedad Botánica de México/Universidad Autónoma Metropolitana, Guadalajara.

Sidwell K. 2012. Oxalidaceae. En: Davidse G., Sousa M., Knapp S. y Chiang F. Eds. Vitaceae a Geraniaceae. Flora Mesoamericana 3 (1). Missouri Botanical Garden. Disponible en línea: <http:// www.tropicos .org/Name/42000267? projectid=3\&langid=66> (Consultado 3 de julio de 2012).

Weller S.G. 1992. Evolutionary modifications of tristylous breeding systems. En: Barrett, S.C. Ed. Evolution and Function of Heterostyly, pp. 247-272, Springer Verlag, Berlín.

Wendt T. 1987. Plantae Uxpanapae III. A new species of Biophytum (Oxalidaceae) and five genera new for the Mexican Flora. Brittonia 39:133-138.

Recibido: 9 de febrero de 2012

Aceptado: 5 de julio de 2012 